\title{
Reflective journaling to decrease anxiety among undergraduate nursing students in the clinical setting
}

\author{
Joely Tara Goodman*1, Melissa Henry ${ }^{2}$ \\ ${ }^{1}$ College of Nursing, Creighton University, United States \\ ${ }^{2}$ School of Nursing, University of Northern Colorado, United States
}

Received: November 21, 2018

Accepted: January 16, 2019

Online Published: January 22, 2019

DOI: $10.5430 /$ jnep.v9n5p 75

URL: https://doi.org/10.5430/jnep.v9n5p75

\begin{abstract}
Objective: Many nursing students experience anxiety in the clinical setting. Increased anxiety impairs students' ability to learn and can negatively affect patient safety. To promote student learning and patient safety, it is imperative that nurse educators identify and implement strategies to decrease nursing students' anxiety. The purpose of this qualitative study was to determine how undergraduate nursing students perceive the impact of writing reflective journals on their anxiety level associated with their first clinical rotation experience early in their program of study.

Methods: Participants were randomly assigned by their clinical group to either write guided reflective journals, non-guided reflective journals, or no reflective journals during their first clinical rotation where they provided patient care. Five individuals from each intervention group were randomly selected to participate in an interview. Themes related to the participants' perceptions of the impact of writing reflective journals on their anxiety were determined through qualitative analysis.

Results and implications: Participants who wrote guided or non-guided reflective journals experienced decreased anxiety associated with their first clinical rotation. Participants in the non-journaling group expressed that they would have benefitted from having a journal assignment. Four themes were identified related to experiences with writing journals: allowed time, identified feelings, assisted with processing, and increased confidence. The findings of this study support the use of reflective journals as a pedagogical intervention to decrease nursing students' anxiety associated with the first clinical experience. Additional benefits of the reflective journaling included taking time to identify and process feelings and increased confidence in future clinical experiences.
\end{abstract}

Key Words: Anxiety, Undergraduate nursing student, Clinical rotation, Reflection, Journal, Confidence, Feelings

\section{INTRODUCTION}

Stress and anxiety in health care professionals have negative results for patient safety and the quality of patient care. ${ }^{[1-5]}$ Particularly in situations with high cognitive load such as clinical practice, anxiety diminishes the capacity to process information for short term action and long-term learning. ${ }^{[3,4,6]}$ When learning is inhibited, inadequate or unsafe nursing care may be provided which can result in undesirable patient outcomes. Cognitive load theory, developed by Sweller, ${ }^{[7]}$ provides an explanation of how cognitive load can impact performance in the clinical setting. When an increased cognitive effort is demanded, such as in the health care environment, the individual providing care can be inhibited from recalling information previously learned. ${ }^{[8]}$ Anxiety affects the processing of an increased cognitive load, and this increased load also has negative implications for new learning to take

*Correspondence: Joely Tara Goodman; Email: joelygoodman@ @ creighton.edu; Address: College of Nursing, Creighton University, United States. 
place in the clinical setting. ${ }^{[9]}$

Nursing students often encounter stress and anxiety in their clinical rotations. Andrew, McGuinness, Reid, and Corco$\operatorname{ran}^{[10]}$ found that $19 \%$ of nursing students report feelings of anxiety associated with their first clinical placement while an additional 3\% dread the first experience of providing patient care. Few strategies have been explored in nursing education to help students minimize or manage the stress and anxiety encountered during clinical rotations. This study aims to examine nursing students' perception of the impact of writing reflective journals on their anxiety related to their first clinical rotation and to develop an understanding of overall perceptions of reflective journal assignments. Identifying strategies that nursing students can utilize while in school and during their clinical practice is an essential step to help mitigate the potential negative impact of anxiety on patient care.

\section{Background}

According to Lazarus and Folkman, ${ }^{[11]}$ a person experiences stress when he or she perceives a situation as harmful or exceeding what he or she can do. While stress is defined as "... the nonspecific response of the body to any demand placed on it" which allows stress to be either helpful or hindering for an individual, negative stress, or distress, results in anxiety (p. 692). ${ }^{[12]}$ Anxiety can be provoked with prolonged stress or multiple stressors. Anxiety refers to a state of apprehension as a response to a perceived threat which results in a disruption of psychological functioning and can be displayed in physiological symptoms including sweating, hypertension, or tachycardia. ${ }^{[13]}$ When health care providers encounter stress in the workplace, patient safety may be compromised, and adverse events may ensue. According to Berland, Natvig, and Gundersen, ${ }^{[14]}$ nurses identify workrelated stress as a risk factor for patient safety. Nielsen, Pedersen, Rasmussen, Pape, and Mikkelsen ${ }^{[15]}$ report a significant association between the occurrence of work-related stressors and involvement in an adverse event. Even though a moderate amount of anxiety is desired because it results in optimal student performance, anxiety levels that are too high or too low decrease the students' performance. ${ }^{[16,17]}$

The stress and anxiety encountered by nursing students in the clinical setting impairs their clinical reasoning with potential negative effects for patients. ${ }^{[3]}$ Harvey, Bandiera, Nathens, and LeBlanc ${ }^{[18]}$ found that health care professionals in high stress situations took longer to respond to and record important vital signs, had an incomplete recall of the history of events during a patient encounter, and had worse scores on a checklist used to measure performance.
Anxiety has a far-reaching impact on the provision of nursing care. Anxiety has a negative impact on the development of relationships with patients and other health care professionals as anxious students tend to distance themselves and refrain from building relationships with others. ${ }^{[16,19]}$ Additionally, anxiety decreases the students' confidence in caring for others. ${ }^{[20]}$

While anxiety impacts performance in the clinical setting, it also has a significant impact on students as they are trying to learn the many aspects of the nursing profession, beyond their role and responsibilities in the clinical setting. According to Palethorpe and Wilson, ${ }^{[21]}$ anxiety severely impairs an individual's ability to learn. When students encounter anxiety, they experience cognitive deficits that can negatively impact their ability to remember material that was previously learned. ${ }^{[6]}$ Specific to nursing, excessive anxiety can negatively influence students' motivation to study, efficacy in the clinical setting, and willingness to become a nurse while also having a negative impact on their ability to learn. ${ }^{[22,23]}$

Three categories of strategies are currently used to decrease anxiety in the clinical setting. These categories include simulation, peer-mentoring, and mindfulness interventions. Simulation is a teaching strategy which has been used in nursing education to decrease students' anxiety. ${ }^{[24,25]}$ While simulation has been found to have a positive impact on student anxiety, the cost associated with simulation may be prohibitive for some nursing programs to implement this strategy to decrease student anxiety. ${ }^{[26,27]}$

Peer mentoring is another strategy which has been used to decrease nursing student anxiety. ${ }^{[28,29]}$ A barrier to implementation of this strategy is the time commitment that is necessary to train and prepare the mentors to serve in this role. Wong et al. ${ }^{[30]}$ found variation in the education provided to mentors, but preparing the mentors is a necessary step for this strategy to help decrease nursing student anxiety.

The third strategy to decrease anxiety in nursing students is mindfulness. Mindfulness, "a form of mental training... that involve[s] stilling or emptying the mind", is a strategy sometimes used to reduce stress for nurses. ${ }^{[31]}$ The different interventions categorized as mindfulness have been found to decrease nursing students' anxiety, but the time commitment from students is a barrier that prohibits students from participating in the activities. The training that would be necessary for nurse educators to implement some of the interventions is also a barrier with this strategy.

One specific teaching strategy that nurse educators often use during clinical rotations is reflective journaling. Studies using reflective journals to measure students' clinical perfor- 
mance ${ }^{[32]}$ and critical thinking ${ }^{[33]}$ have been completed, but there were no studies located assessing the potential of reflective journals as a strategy to help decrease anxiety. Reflective journals may be formatted as a guided reflection or as an unguided reflection. Guided reflections may help students move beyond a description of events in the clinical setting and facilitate a thorough contemplation of clinical experiences, ${ }^{[34]}$ but there is lack of research which investigates differences in student outcomes related to the format of the reflective journal assignment. While written reflective journals are one format of reflection utilized in nursing education, it is also possible for nursing students to reflect on clinical experiences through other modalities. Other possible methods of reflection include video recording and audio recording. Possible advantages of electronic reflection assignments include that they provide various ways to capture an experience and may support student-centered learning. ${ }^{[35]}$ Dyment, O'Connell, and Boyle ${ }^{[35]}$ identify potential downfalls of using technology for journaling including that students may not engage in an in-depth reflection as they tend to provide an immediate response about the experience. Written reflective journals do not require a large time commitment from students or faculty, and there are no additional sessions outside of class that need to be facilitated. Since reflective journals are often assigned during clinical rotations, it is beneficial for nurse educators to have a complete understanding of all positive impacts of these writing assignments.

\section{METHOD}

A qualitative research design was used for this study which contributed to a more complete understanding of the students' perception of the reflective journals and how the intervention might be implemented to achieve the desired result of decreasing anxiety. Conducting personal interviews after the participants completed their first clinical rotation and wrote the reflective journals allowed for the collection of deeper information about nursing students' experiences with using reflective journals and feedback about the most effective way to structure the reflective journal assignments.

\subsection{Setting and participants}

The study took place at a college of nursing in a private university located in Midwest United States. This university offers the nursing program on a larger urban campus and on a smaller rural campus. The researcher works on the smaller campus, and participants for this study were recruited from the larger campus. To be included this study, research participants had to be 19 years of age or older, able to read and speak English, and participate in the first clinical rotation where they provide patient care. This nursing school has approximately 110 students in each traditional, or

Published by Sciedu Press non-accelerated, program cohort and approximately $55 \mathrm{stu}$ dents in each accelerated program cohort. Most students in the traditional program are Caucasian females in their early 20s. The accelerated nursing program typically enrolls more males, older students, and individuals of different ethnicities. The accelerated nursing program at this university is a three-semester program that lasts 12 months. Students in the accelerated program must have a previous bachelor's degree and successfully complete pre-requisites before enrolling in the nursing courses. Students from both programs were invited to participate in the study.

Participants were assigned to clinical groups by their instructors, who were not involved with the planning of this study or the collection of data. Thirteen clinical groups of traditional students and six clinical groups of accelerated students were scheduled during the semester this study was conducted. Participants in these 19 clinical groups were randomly assigned to write either guided reflective journals (7), non-guided reflective journals (6), or no reflective journals (6) using Research Randomizer ${ }^{[36]}$ for the first clinical rotation where they provided direct patient care.

Parts of Gibbs' reflective cycle ${ }^{[37]}$ were used to develop the prompts and questions for the guided reflective journal assignment. This cycle encourages individuals to use steps to reflect on an experience. The cycle includes the following six phases: description, feelings, evaluation, analysis, conclusion, and action plan. For the first phase, participants were asked to "describe an experience in the clinical setting where" they felt anxious. For the second phase, participants explored the feelings they had during the clinical rotation by responding to questions such as, "Try to describe the feelings you had during this experience" and "Did your feelings affect your actions?" During the evaluation phase, the participants identified "what was good or bad about this experience?" During the analysis phase, the participants were asked, "Why do you think you had these feelings?" In the conclusion, participants considered the question of, "Was there anything you could have discussed with a peer or instructor?" The final phase of Gibbs' reflective cycle allowed the participant to suggest a plan if a similar event happens again by responding to the question, "If you experience feelings of anxiety in the future related to the clinical rotation, what will you do?".

Gibbs' reflective cycle is applicable for nurses because it can be adapted to the different situations that health care professionals encounter in the clinical setting. ${ }^{[38]}$ The University of South Wales ${ }^{[39]}$ developed a list of questions for students to use during the reflective cycle, and some questions from this list were modified for use in this study. The research participants who wrote non-guided reflective journals received 
instructions about how to complete their journals which included for them to write a one-to-two-page reflection about any feelings they had related to their clinical experience.

Participants in the two groups who wrote journals were assigned to write their first journal prior to their first clinical day, a second journal after week two of their first clinical rotation, and a third journal after the fourth and final week of their first clinical rotation. Research participants in the group with no reflective journals (control group) did not have any journals assigned during the first clinical rotation, and journal assignments were not mentioned during the clinical orientation. These participants had an alternate assignment to equate the workload for participants in the other clinical groups.

An email was sent to all 156 students eligible for this study after the second week of the first clinical rotation to recruit participants. It was anticipated that five to six participants would be needed from each group of participants to reach data saturation. Five participants from the guided reflective journal group, six participants from the non-guided reflective journal group, and ten participants from the control group that did not write reflective journals volunteered to participate in an interview. Using Research Randomizer, ${ }^{[36]}$ five research participants from each group willing to share their experiences in an interview were randomly selected and contacted to schedule an interview. Nine interview participants were enrolled in the traditional nursing program, six were enrolled in the accelerated nursing program, and all interview participants were female.

\subsection{Ethical considerations}

Ethical approval was obtained from the Institutional Review Boards from the university where the participants were enrolled as undergraduate nursing students and the university where the researcher was enrolled as a doctoral student. Verbal and written consents were obtained before each interview. The research participants were notified that they could decline to answer any questions and could withdraw from the study at any time without penalty or loss of benefits. Due to the nature of conducting interviews, it was not possible for the research participants to be anonymous to the researcher, but participants were not known to each other unless they disclosed this information. Each interview participant chose a pseudonym which is used in the dissemination of results. The formal benefit to participating in the interview was a $\$ 25$ Starbucks gift card that was provided for each participant. All individuals were provided contact information for a counseling center they could contact if they had feelings of anxiety they wanted to discuss with a professional.

\subsection{Data collection}

Interviews, which lasted approximately 20 minutes, were used at the end of the participants' first semester. The interviewer was located in a private room on campus or in the researcher's home while the research participants chose their location as long as they had an internet connection to access WebExTM, a web-based video conferencing system. The audio of the interviews was recorded using PanoptoTM with an mp3 audio recorder used as a backup. The semistructured interview consisted of open-ended questions that were generated in advance and piloted with nursing students who were near the end of their program and not eligible to participate in the study. No changes were made based on the feedback from the pilot study. Additional questions were asked during the interviews, as needed, based on the participants' responses. ${ }^{[40]}$

\subsection{Data analysis}

The transcribed data were analyzed using criteria discussed by Saldana. ${ }^{[41]}$ In summary, magnitude coding was conducted to analyze a portion of the data about participants' perception of the impact of writing journals on their anxiety allowing some level of "quantitizing" how much the reflective journals impacted the participants' anxiety. ${ }^{[41]}$ In Vivo coding was used for the first-cycle coding of the data about participants' experiences with writing journals to give priority to the voice of the participant. Themes were identified from these codes. Additionally, analysis revealed common themes related to experiences with writing reflective journal assignments for individuals regardless of the format of the journal they were assigned. Due to the finding of common themes, the qualitative results were combined for participants who wrote guided and non-guided reflective journals for a portion of the analysis.

Criteria to enhance the rigor of qualitative data were maintained through assessing credibility, dependability, and transferability. This was done through encouraging honesty, performing member checks, completing an audit trail of how the data were collected and analyzed, thick description of the setting and study findings, and researcher bracketing.

\section{Findings}

Four themes related to participants' experiences with writing journals emerged from the interviews. These themes included allowed time, identified feelings, assisted with processing, and increased confidence.

\subsection{Perceived impact on anxiety}

During the interview, participants were asked what impact, if any, they felt that writing the reflective journals had on their

ISSN 1925-4040 E-ISSN 1925-4059 
anxiety. If the participants indicated they felt the journal assignment did impact their anxiety, they were asked if the impact was slight, moderate, or significant.

All five participants in the guided reflective journal group felt that writing reflective journals impacted their anxiety. Of those five, three participants thought writing had a slight to moderate impact while two participants thought writing the reflective journals had a moderate impact on anxiety. Kimberly discussed the freeing feeling she had from writing the journals when she said, "I' $m$ writing about it on this paper and it's out of me now." Brittany discussed that writing the journals helped decrease her anxiety each week:

I had also kind of determined things that made me anxious from the first one [journal] and why I had them [anxieties], so going into the second week, it was a little bit easier and I was less nervous. Even the third week, I was even less nervous.

Jae commented "the journal made me feel less anxious... it helped to decrease anxieties I had about not doing enough." Grace felt "writing down and acknowledging what my anxieties were helped... it allowed me to assess and reassess myself throughout the weeks." Allie shared how "realizing that I am competent... make me less nervous for the next time."

Of the three participants in the non-guided reflective journal who felt that writing reflective journals impacted their anxiety, one participant thought writing had a slight impact, one thought it had a slight to moderate impact, and one thought it had a moderate impact.

Molly discussed, "I think that the reflective journals had a very positive impact on me related to anxiety and just, I think, in general, I found it to be a very positive tool." She also shared, "I was probably able to decrease my anxiety in future rotations because I was able to recall those experiences and how I handled them in the past." Hope mentioned, "I think it helped me put it on paper... [writing] allowed me to really recognize that you can have a little anxiety." Michelle stated, "It definitely lowered my anxiety." There were two interview participants from the non-guided reflective journal group who did not feel that writing the journals necessarily impacted their anxiety.

Five participants who were not assigned reflective journals during their first clinical rotation also participated in an interview. One purpose of this interview was to determine if these participants felt like they would have benefitted from writing journals. All five participants thought they would have seen benefits from writing reflective journals. Danne

Published by Sciedu Press said, "I wish we would have had one, especially since that was our first rotation. I think I would have seen a lot of growth." Amanda commented, "Having a reflective journal might have been nice because it would have been more, your thoughts and your feelings." These five participants could see value in reflecting on experiences. Casey shared, "I think that it's worthwhile to reflect on what you're doing while you're doing it and afterward so you can see the value." Renee also mentioned the value of reflecting when she said, "I think reflecting is super important. . I I don't really sit down to reflect on my own which, I guess, I could benefit from." Robin elaborated on the potential value of reflective journals,

I do think that they're helpful. If you have something to reflect, I think it's really helpful to look back and try to remember either good things or bad things, especially trying to think of good things that you've done. Because I feel that sometimes you forget about those with all the rush and stuff, just small moments where you made someone happy or were able to help someone do something that they might not have otherwise been able to do.

\subsection{Format of journals}

During the interview, the participants discussed their opinion of the format of the journal as some journals were guided with specific prompts and others were non-guided for an open reflection. The participants who did not write reflective journals discussed which format they would prefer for an assignment. The participants' opinion of the format and what they prefer varied.

Jae wrote guided reflective journals and said, "I feel like the prompts were good because they guided you in the right direction and where to aim your reflection... I do enjoy having prompts more than just open reflection." Brittany also wrote guided reflective journals and shared,

I think it allowed you to give a lot of details about your feelings in the moment and reflecting on why you had them... the structured format was better for me because then I actually truly learned something out of it and that could benefit me in the future... if it would have been just an open format, I would have not probably thought back on why I was feeling those. I would have talked about the anxious time or how my clinical went, and I don't think I would have truly reflected.

Other participants in the guided reflective journal group shared similar thoughts. Grace said, "If I have a prompt, 
it's much easier for me to go from there... It gave me a theme to focus on." Allie thought some prompts are "nice because it brought out points that you haven't thought of before."

However, Allie struggled with feeling forced to write to answer the prompts and mentioned it would be beneficial to "have some prompting questions that you could include. Not necessarily answer these questions but like, 'think about $\mathrm{x}, \mathrm{y}$ and $\mathrm{z}$ in your reflection.",

Participants who wrote non-guided reflective journals also shared their opinions about the format of the reflective journal. Meredith commented, "I really liked it [journal] open because then it gave me the opportunity to talk about anything that I wanted to." However, she also mentioned that "there are a few people who are like 'This is too open, what am I supposed to talk about?" "Meredith also mentioned it may be helpful to have "examples of prompts that you could pull into it." Molly liked the open format of the non-guided journal "because it really allows the student to take it wherever they want... having that open format allowed them and makes them feel like it's okay to talk about really, whatever you want to talk about." Molly went on to say,

It's difficult because we go through so much very structured, this is what you need to write about, these are the three things in the rubric... so, sometimes, I think it is hard when it is an open format like that because in my mind sometimes I was kind of like what are they looking for. .. so I can understand how for some students that might have posed a difficulty for them.

Michelle also liked the open format and said, "I was able to write about anything I wanted to write about. . . by being so open, I was able to talk about the things I actually wanted to talk about." Julie shared a similar experience, "I liked the open... journal format. I don't have to put anything in an exact order. It's just whatever comes to mind... I think it's more genuine that way."

All five participants who did not write reflective journals discussed which format of reflective journal they would prefer for an assignment. Of these five participants, four individuals thought they would prefer prompts while Danne said, "It depends on the weeks that they fall" because sometimes the questions might not relate to clinical experiences that week. Amanda said, "I think having the option of a prompt would be really good in case if you didn't have something on top of your mind. It could just get your brain triggered." Renee also mentioned, "I think it's kind of hard to think of what to reflect on and maybe, just having options would probably be helpful. They can kind of spearhead where you're going to go with your reflection." Robin shared a similar thought by saying, "I think a prompt would've been good... you know what you're supposed to be reflecting on more." By the time of the interview, Robin had written a journal assignment for a different clinical rotation and shared, "That was an open reflection and I felt like it was just more difficult because... I didn't really know what they wanted from it, and that made it a little more difficult."

\subsection{Impression of writing journals \\ 3.3.1 Theme 1: Allowed time}

The first theme of "allowed time" refers to participants indicating that being assigned reflective journals allowed them to take the time to reflect on their experiences in the clinical setting. Participants from both the guided reflective journal group and non-guided reflective journal group commented about how the journal assignments allowed them to take the time to reflect on their experiences in the clinical setting. Participants who wrote guided reflective journals appreciated taking the time to consider the experiences they had in the clinical setting. As Jae shared, "It was really good to be able to have that time to truly think back on it [experiences] and not just go through the clinical and then move on." By taking this time to think through and write a guided reflection on experiences, participants reported the opportunity to think back on their clinical day and identify areas that went well, didn't go well, and how they might improve on those areas for future clinical experiences. As Brittany stated, "I actually took time to think about how I was feeling, why I was feeling that way, and maybe how I can improve for the next time."

Participants in the non-guided reflective journal group also appreciated the opportunity to reflect as Molly discussed,

It was great to be able to really take time to think about, 'what were my feelings about today? Why was I feeling anxious? Why did I have that nervousness? What helped that? What caused that anxiety to come about?'

Through taking time to reflect and write the journals, participants in the non-guided reflective journal group commented about the opportunity to dive deeper into the care they provided for a patient and being able to reminisce about how they helped the patients they cared for. Hope stated, "the reflections allowed me the chance to stop and think and dive deeper into why I was caring for the person."

\subsubsection{Theme 2: Identified feelings}

Participants who wrote reflective journal assignments were able to identify many feelings during the writing process. 
By recognizing triggers for feelings of anxiety, participants in the guided reflective journal group were also able to consider how they would act differently in the future when faced with the same triggers for these feelings of anxiety. Brittany discussed,

I was thinking about reasons why I get anxious, and then some of them are actually things that maybe I don't need to be anxious about, and for the future, I can kind of like talk myself down and think like, 'Oh, this is something you don't need to be anxious about.'

Grace had a similar experience and shared, "writing them [journals] for four weeks straight really helped me identify what my triggers are and what are good personal coping techniques I use."

Participants in the non-guided reflective journal group also described the writing process as helpful in being able to identify feelings in the clinical setting. Meredith discussed,

Until I went to write the reflection journal, I didn't realize how much... I was actually impacted by it [clinical experience]... At the end of the day of when you went to write those, it was nice to know how you were actually feeling during the day.

Julie also discussed identifying feelings and considering how this might impact future actions: "It [reflective journals] did help me realize things. Just recognizing... what did make me worried... knowing how you would possibly react in that situation, should it occur again, and know how to control your feelings."

Some participants who wrote non-guided reflective journals also discussed how the process of writing allowed them to identify their growth in the clinical rotation and how that could benefit them in the future. Molly shared, "there was a lot of learning, a lot of growing that was occurring. It was really nice to have an outlet to express that." Julie discussed the value of writing her reflections:

I know what I learned, but putting it down in writing form, I'm able to explain it more and go into depth of how the specific actions or concepts could benefit me in future rotations and in my career as a nursing student.

\subsubsection{Theme 3: Assisted with processing}

Writing journals provided participants with the opportunity to process what they experienced during the clinical day. Participants who wrote guided reflective journals shared about

Published by Sciedu Press being able to make connections through writing the journals. Brittany shared the impact of writing journals on processing her feelings when she said, "they helped me to actually critically think back on what was going on and how I was feeling." Allie also discussed,

Writing these reflective journals, it really helped me process what we worked through that day and then caring for those patients with issues that I've never been exposed to... it was very beneficial and allowed me to process and... really solidified that connection.

As participants reflected on their experiences and formulated their thoughts, they were able to make connections related to what they learned in the clinical setting which increased their comprehension. Allie shared about this, "they're [reflective journals] super beneficial because they've allowed me to process how did I really do that day with that patient."

Writing about experiences in the clinical setting lifted a burden for participants. Kimberly discussed, "reflecting on things has always been like, write things on paper and it's out there and it definitely lifts that burden that I had on my shoulders." The writing assignments also allowed participants to justify their feelings. Allie specifically commented on how the prompts for the guided reflective journals assisted with her feelings of anxiety when she stated,

They justify feelings of anxiety for me. It made it seem like it was something that was okay to have. By asking about it and having you work through it, it let you know that it's normal to be nervous for this and this is how you work through it in a healthy manner. It kind of gave you a process to think through things that weren't as familiar.

Similarly, participants in the non-guided reflective journal group commented about processing and making connections through the writing process. Meredith shared, "being able to write the reflection journals... definitely helped me process that [what happens in clinical] a bit more. And I think I found that I was realizing things and making connections that I originally wasn't without writing the journal." Hope shared her experience of processing feelings through writing journals when she said,

Being able to write about my experience... helped me think through the day. I was able to be like, 'Okay. Well, maybe I'm going to look at this scenario a little differently next time or provide this type of care different next week.' 
In addition, Michelle identified that "the reflective journal is a way to come back to center and go into the next week with my slate clean." This manner of processing enabled the participants to be more attentive and prevented the clinical experiences from being lost and gone at the end of the clinical day. Molly also discussed this theme of processing:

I think having the reflection is a really nice way to be able to go back and think, 'Well, no I don't want to push what happened out of my mind', think about what were some of those tough moments that I had or what were some of my strengths. That way it wasn't just like the clinical day happened and then nothing more comes out of it. So, I think it really was beneficial to have that time to remember what happened to the day as a whole because that is not just like those experiences are lost and gone somewhere.

\subsubsection{Theme 4: Increased confidence}

Writing reflective journals allowed participants to recognize areas of competence. The evidence that participants had developed skills to use in the real world instilled selfconfidence. Participants were able to carry these feelings of confidence forward into future experiences in the clinical setting.

Participants in the guided reflective journal group shared about the influence of the prompts for the guided reflective journal on feelings of confidence. When faced with experiences in the clinical setting that conjured up similar feelings of anxiety, participants reported being able to recall previous encounters with anxiety and the successful ways of dealing with these feelings of anxiety. As Brittany discussed, "I recognize what the triggers were and then I calmed myself. . . It was knowing that I had triggers but then remembering I'd overcome those triggers previously, so I'll be able to overcome them again." By knowing they had overcome these feelings before, the participants had the confidence that they could overcome these feelings again. Allie shared,

Reflecting on it [clinical experience], realizing that I am competent and that everything was okay, they make me less nervous for the next time that I have to give a different type of treatment that I've never given before. It just reinstilled your own confidence because you realize, 'okay, I was scared. I did it. It was fine. I did a good job, and I can do this moving forward.'

Kimberly also mentioned how journals contributed to increased confidence in future clinical experiences when she said, "it [writing reflective journals] gave me a lot more confidence because it's almost like my own personal evidence that I developed more skills and I'm able to do this in the real world." Grace identified the opportunity to carry these feelings of confidence forward, "Thinking and reflecting upon that confidence... and what I wrote about helped me follow it through and carry that attitude through."

A participant in the non-guided reflective journal also identified increased confidence because of writing journals when she shared "I remember through that reflective journal that happened yesterday, and so now I have that knowledge that I can apply moving forward" (Molly). Michelle shared a similar impact of writing journals as she said, "Identifying those weaknesses and... being able to write that out and how I'm going to work on it. This definitely made me more confident going week to week."

\section{Discussion}

This study identifies an additional strategy which may be implemented by nurse educators to decrease the anxiety associated with the first clinical placement for nursing students. While studies have been done to determine the impact of writing reflective journals on students' critical thinking ${ }^{[33]}$ and clinical performance, ${ }^{[32]}$ there have been no studies located that evaluated the perception of writing journals on students' anxiety.

Of the 10 interview participants who wrote reflective journals during their first clinical rotation, eight participants indicated that writing journals decreased their anxiety. All five participants who wrote guided reflective journals felt that the journals helped decrease anxiety while three participants who wrote non-guided reflective journals felt that the journals helped decrease anxiety. The participants believed the impact of writing journals varied from slight to moderate. Other studies located in the literature about interventions to decrease nursing student anxiety did not report findings about the participants' perception of the effectiveness of the intervention.

\subsection{Experiences with writing reflective journals}

Results from this study indicate that nursing students saw value in and reported benefits of journaling whether there were structured questions to respond to in the journal or if the format was an open reflection on their experiences in the clinical setting. This finding is supported by a review which also found that nursing students describe positive aspects of journaling regardless of the format. ${ }^{[34]}$ 


\subsubsection{Theme one: Allowed time}

Theme one was characterized by the appreciation of the research participants who wrote reflective journals to take the time to think back on their experiences in the clinical setting. Participants expressed that being required to write a journal allowed them to have time to reflect on their feelings instead of just forgetting about the clinical day once it was over.

This finding of participants appreciating the time to reflect on their experiences is not a finding that was found in other literature about reflective journaling. However, it is beneficial for nurse educators to know that assigning the students to write one or two pages for each reflective journal allowed enough space to reflect on experiences, but the length was not too demanding of the students' time and attention. Nurse educators need to consider the weekly assignments that students are asked to complete and ensure that assignments meant to help reduce anxiety, such as reflective journals, are manageable along with the other assignments.

\subsubsection{Theme two: Identified feelings}

Theme two was characterized by participants being able to identify feelings from the clinical experience as they wrote their journals. Participants identified the ability to identify triggers for anxious feelings. By identifying these triggers, participants reported being able to recognize these feelings in the future and have better control over their anxiety. Participants who wrote journal assignments also reported being able to detect areas of growth and where they should focus for improvement in future clinical experiences. This finding is consistent with a previous study which found that nursing students who wrote journals during their clinical rotation identified that the assignments assisted with recognizing personal strengths and weaknesses. ${ }^{[42]}$

The finding of participants being able to identify feelings in the clinical setting is similar to the findings of Barnes. ${ }^{[33]}$ Barnes ${ }^{[33]}$ found that students can consider alternate ways to approach situations when they reflect on personal experiences. This previous study also found that the writing process allowed students to recognize personal strengths and areas for improvement, which aligns with the findings of the current study.

\subsubsection{Theme three: Assisted with processing}

Theme three was characterized by participants being able to process their experiences during the clinical day. By processing these experiences, participants were also able to make connections that they did not make prior to writing the journal. These connections increased the participants' comprehension of what they experienced during the clinical day. Van Horn and Freed ${ }^{[43]}$ report nursing students made connections between material learned in class and experi-

Published by Sciedu Press ences in the clinical setting when writing reflective journals with guiding questions. A literature review also indicated that journaling allowed students to discover connections and gain insight into practice through the reflective process. ${ }^{[44]}$

Participants also shared that writing reflective journals lifted a burden and helped wipe the slate clean for the next week. These findings coincide with the framework for this study, the Cognitive Load Theory. If the process of writing journals enables nursing students to process their feelings and experiences from the clinical day, the students will be better able to focus on providing safe and high-quality care for their assigned patients.

\subsubsection{Theme four: Increased confidence}

Theme four was characterized by participants indicating that reflective journaling allowed for the recognition of areas of competence. By identifying areas of competence, participants reported an increase in self-confidence. This confidence was a feeling that participants reported carrying forward into future clinical experiences.

As Eysenck et al. ${ }^{[45]}$ stated with regards to the Cognitive Load Theory, students with increased anxiety also worry more. With increased confidence, this amount of worrying could be diminished which would also increase the available working memory and enhance student learning. Barnes ${ }^{[33]}$ found that reflective journaling increased student confidence when communicating with patients. Participants in this study did not specifically identify an increase when communicating with patients, but they indicated an overall increase in confidence.

\section{Conclusion}

The aim of this study was to examine nursing students' perception of the impact of writing reflective journals on their anxiety related to the clinical setting and to develop an understanding of overall perceptions of reflective journal assignments. Fifteen participants described their perceived actual or potential impact of writing reflective journals on their anxiety level and their experiences with writing journals, if applicable. Participants indicated that writing journals helped decrease their anxiety associated with the clinical setting, or they thought they would benefit from writing journals if they had the opportunity to have this assignment. Four themes emerged related to nursing students' experience with writing reflective journals: allowed time, identified feelings, assisted with processing, and increased confidence. There was not a conclusive finding about whether reflective journals should be guided or non-guided as participants' opinion about this varied.

Ultimately, an intervention aimed at decreasing anxiety could 
be considered effective if individuals perceive this impact. The results of this study suggest that writing reflective journals, whether guided or non-guided, can help decrease nursing students' anxiety associated with the clinical setting. There are also additional benefits to writing reflective journals that were revealed through this study. As nursing education continues, more evidence will be needed to guide interventions that can decrease nursing students' anxiety associated with the clinical setting. Future research, as suggested in this study, will contribute additional information about the viability of reflective journals as a strategy to decrease anxiety.

\subsection{Limitations}

One limitation of this study includes that the interviews were held at a time that resulted in participants recalling experiences from a few weeks earlier. It is possible that their memories were inaccurate, or the participants may have left out details on purpose or accidently. Additionally, the participants in this study were enrolled in different types of nursing programs. While the clinical rotations for the participants in the traditional and accelerated nursing programs are similar, participants enrolled in the accelerated nursing program have a slightly different curriculum. It is possible that the participants experienced differences related to anxiety because of the differences in curriculum and clinical setting. The research participants also had different clinical instructors, and this may have impacted the anxiety nursing participants encountered related to the clinical rotation. In the 19 clinical groups, all students in each group were assigned to the same intervention group for the study which helped control for this limitation. The participants in the study are from one university which may limit the external validity of the findings. Nursing students enrolled in associate degree programs, on the smaller rural campus of the nursing program used in this study, or from a different part of the country may have provided different results.

\subsection{Recommendations and implications}

The results of this study suggest that guided and non-guided reflective journals were effective in decreasing nursing student anxiety. Participants shared many positive aspects of writing reflective journals, and individuals without journal assignments indicated they see the value in reflection. Given the known detrimental effects of anxiety on nursing student learning and performance in the clinical setting, it is recommended that nurse educators consider assigning reflective journals to nursing students during their clinical rotations.

Reflective journals do not have any expense associated with their implementation. There is also no additional equipment that is needed for nursing students to write reflective journals. These characteristics contribute to the ease and feasibility of assigning reflective journals.

The differing opinions of the participants related to the format of the journal being guided or non-guided is important to consider for future implementation of this intervention. A recommendation is to have some guiding prompts available for students to consider but not require each prompt to be answered in the journal assignment. This would allow for some triggers for individuals that prefer having more direction while also leaving the format open to allow creativity for individuals who have that preference.

The nurse educator should discuss the reflective journal assignments with the students when the students first encounter this assignment to provide rationale and to help students see value in writing the journal. During this discussion, the educator should also provide information about any specific expectations of the reflective journal to prevent students from being unsure of what the faculty member is looking for in their written work.

Findings from this study indicate that reflective journal assignments can help decrease nursing study anxiety associated with the first clinical rotation. It would be helpful to have a study conducted with more participants from different nursing programs to evaluate if this effect is similar with a larger, more diverse, sample. A longitudinal study that measured nursing students' anxiety throughout the entire first semester or first year with the intervention groups in effect for that duration would provide additional information about the impact of writing reflective journals on anxiety. While written reflective journals were used for this study, it is relevant to note that reflection could also be completed through audio or video recordings. Additional research about the effectiveness of different methods of reflection on decreasing students' anxiety would add to nursing science.

\section{CONFLicts OF InTEREST Disclosure}

The authors declare that there is no conflict of interest.

\section{REFERENCES}

[1] Burbach BE, Thompson SA, Barnason SA, et al. Student-perceived influences on performance during simulation. Journal of Nursing Education. 2016 Jun 29; 55(7): 396-8.
[2] Cheung RY, Fong Au TK. Nursing students' anxiety and clinical performance. Journal of Nursing Education. 2011 May 1; 50(5): 286-9. PMid:21323251 https://doi.org/10.3928/01484834-20110 131-08 
[3] Pottier P, Dejoie T, Hardouin JB, et al. Effect of stress on clinical reasoning during simulated ambulatory consultations. Medical Teacher. 2013 Jun 1; 35(6): 472-80.

[4] Shipton SP. The process of seeking stress-care: Coping as experienced by senior baccalaureate nursing students in response to appraised clinical stress. Journal of Nursing Education. 2002 Jun 1; 41(6): 243-56. PMid: 12096773

[5] Steven A, Magnusson C, Smith P, et al. Patient safety in nursing education: Contexts, tensions and feeling safe to learn. Nurse Education Today. 2014 Feb 1; 34(2): 277-84.

[6] Khan, ZA., Zafar, S. The effects of anxiety on cognitive processing in English language learning. English Language Teaching. 2010 May 18; 3(2): 199-209.

[7] Sweller, J. Cognitive load during problem solving: Effects on learning. Cognitive Science. 1988 Apr; 12(2): 257-85. https: //doi.org/10.1207/s15516709cog1202_4

[8] Chen R, Grierson LE, Norman GR. Evaluating the impact of highand low-fidelity instruction in the development of auscultation skills. Medical Education. 2015 Mar; 49(3): 276-85. PMid:25693987 https://doi.org/10.1111/medu.12653

[9] Darke S. Effects of anxiety on inferential reasoning task performance. Journal of Personality and Social Psychology. 1988 Sep; 55(3): 499-505. PMid:3171920 https://doi.org/10.1037/00 22-3514.55.3.499

[10] Andrew N, McGuinness C, Reid G, et al. Greater than the sum of its parts: Transition into the first year of undergraduate nursing. Nurse Education in Practice. 2009 Jan1; 9(1): 13-21.

[11] Lazarus RS, Folkman S. Stress, appraisal and coping. Springer; 1984.

[12] Selye H. The evolution of the stress concept: The originator of the concept traces its development from the discovery in 1936 of the alarm reaction to modern therapeutic applications of syntoxic and catatoxic hormones. American Scientist. 1973 Nov 1; 61(6): 692-9. PMid:4746051

[13] Ratanasiripong P, Park JF, Ratanasiripong N, et al. Stress and anxiety management in nursing students: Biofeedback and mindfulness meditation. Journal of Nursing Education. 2015 Aug 25; 54(9): 520-4.

[14] Berland A, Natvig GK, Gundersen D. Patient safety and job-related stress: A focus group study. Intensive and Critical Care Nursing. 2008 Apr 1; 24(2): 90-7. PMid:18096388 https://doi.org/10 $.1016 / j$. iccn. 2007.11.001

[15] Nielsen KJ, Pedersen AH, Rasmussen K, et al. Work-related stressors and occurrence of adverse events in ED. American Journal of Emergency Medicine. 2013 Mar 1; 31: 504-8.

[16] Melincavage SM. Student nurses' experiences of anxiety in the clinical setting. Nurse Education Today. 2011 Nov 1; 31(8): 785-9. PMid:21641701 https://doi.org/10.1016/j.nedt.2011.05 .007

[17] Moscaritolo LM. Interventional strategies to decrease nursing student anxiety in the clinical learning environment. Journal of Nursing Education. 2009 Jan 1; 48(1): 17-23. PMid:19227751 https: //doi.org/10.3928/01484834-20090101-08

[18] Harvey A, Bandiera G, Nathens AB, et al. Impact of stress on resident performance in simulated trauma scenarios. Journal of Trauma. 2011; 72(2): 497-503.

[19] Karimollahi M. An investigation of nursing students' experiences in an Iranian psychiatric unit. Journal of Psychiatric and Mental Health Nursing. 2012 Oct; 19(8): 738-45. PMid:22092998 https://doi.org/10.1111/j.1365-2850.2011.01850.x

[20] Khalaila R. Simulation in nursing education: An evaluation of students' outcomes at their first clinical practice combined with simulations. Nurse Education Today. 2014 Feb 1; 34(2): 252-8.
PMid:24060462 https://doi.org/10.1016/j.nedt.2013.08 .015

[21] Palethorpe R, Wilson JP. Learning in the panic zone: Strategies for managing learner anxiety. Journal of European Industrial Training 2011 Jun 7; 35(5): 420-38. https://doi.org/10.1108/030905 91111138008

[22] Bowie BH. Clinical performance expectations: Using the "youattitude" communication approach. Nurse Educator. 2010 Mar 1; 35(2): 66-8. PMid:20173590 https://doi.org/10.1097/NNE. ob013e3181 ced8be

[23] Chen JY. Morale and role strain of undergraduate nursing students in a pediatric clinical setting. Journal of Nursing Research. 2010 Jun 1; 18(2): 144-53. PMid:20592660 https://doi .org/10.1097/JNR. ob013e3181e365a0

[24] Dearmon V, Graves RJ, Hayden S, et al. Effectiveness of simulationbased orientation of baccalaureate nursing students preparing for their first clinical experience. Journal of Nursing Education. 2012 Dec 1; 52(1): 29-38.

[25] Gore T, Hunt CW, Parker F, et al. The effects of simulated clinical experiences on anxiety: Nursing students' perspectives. Clinical simulation in nursing. 2011 Sep 1; 7(5): e175-80.

[26] Lapkin S, Levett-Jones T. A cost-utility analysis of medium vs high-fidelity human patient simulation manikins in nursing education. Journal of Clinical Nursing. 2011 Dec; 20(23-24): 3543-52. PMid:21917033 https://doi.org/10.1111/j.1365-2702.20 $11.03843 . x$

[27] Zendejas B, Wang AT, Brydges R, et al. Cost: The missing outcome in simulation-based medical education research: A systematic review. Surgery. 2013 Feb; 153(2): 160-76.

[28] Walker D, Verklan T. Peer mentoring during practicum to reduce anxiety in first-semester nursing students. Journal of Nursing Education. 2016 Oct 27; 55(11): 651-4. PMid:27783820 https: //doi.org/10.3928/01484834-20161011-08

[29] Zentz SE, Kurtz CP, Alverson EM. Undergraduate peer-assisted learning in the clinical setting. Journal of Nursing Education. 2014 Mar 1; 53(3): S4-S10. PMid:24512330

[30] Wong C, Stake-Doucet N, Lombardo C, et al. An integrative review of peer mentorship programs for undergraduate nursing students. Journal of Nursing Education. 2016 Feb 27; 55(3): 141-9.

[31] Guillaumie L, Boiral O, Champagne J. A mixed-methods systematic review of the effects of mindfulness on nurses. Journal of Advanced Nursing. 2017 May; 73(5): 1017-34. PMid:27706912 https://doi.org/10.1111/jan.13176

[32] Taylor-Haslip V. Guided reflective journals depict a correlation to the academic success of nursing students. Teaching and Learning in Nursing. 2010 Apr 1; 5: 68-72. https ://doi.org/10.1016/j. teln.2010.01.002

[33] Barnes CA. Reflective journaling: Writing down their feelings, students feel more comfortable providing patient care. Advance Healthcare Network for Nurses. 2010.

[34] Craft M. Reflective writing and nursing education. Journal of Nursing Education. 2005 Feb; 44(2): 53-57. PMid:15719711

[35] Dyment JE, O'Connell TS, Boyle I. The intersection of web 2.0 technologies and reflective journals: an investigation of possibilities, potential and pitfalls. Journal of Outdoor Recreation, Education, and Leadership. 2011; 3(3): 137-150.

[36] Urbaniak GC, Plous S. Research Randomizer. 2017. Available from: https://www.randomizer.org

[37] Gibbs, G. Learning by doing: A guide to teaching and learning methods. Oxford Further Education Unit; 1988. 
[38] Wilding PM. Reflective practice: a learning tool for student nurses. British Journal of Nursing. 2008 Jun 12; 17(11): 720 4. PMid:18773590 https://doi.org/10.12968/bjon.2008.1 7.11.29644

[39] University of South Wales. Gibbs' Model of the Reflective Cycle. 2013.

[40] Chan ZC, Fung Y, Chien W. Bracketing in phenomenology: Only undertaken in the data collection and analysis process. The Qualitative Report. 2013; 18(30): 1-9.

[41] Saldana J. The coding manual for qualitative researchers. Sage; 2015.
[42] Ruthman J, Jackson J, Cluskey M, et al. Using clinical journaling to capture critical thinking across the curriculum. Nursing Education Perspectives. 2004 May; 25(3): 120-3.

[43] Van Horn R, Freed S. Journaling and dialogue pairs to promote reflection in clinical nursing education. Nursing Education Perspectives. 2008 Jul 1; 29(4): 220-5. PMid:18770951

[44] Blake TK. Journaling: An active learning technique. International Journal of Nursing Education Scholarship. 2005 Apr 15; 2(1).

[45] Eysenck MW, Derkashan N, Santos R, et al. Anxiety and cognitive performance: Attentional control theory. Emotion. 2007 May; 7(2): 336-53. 